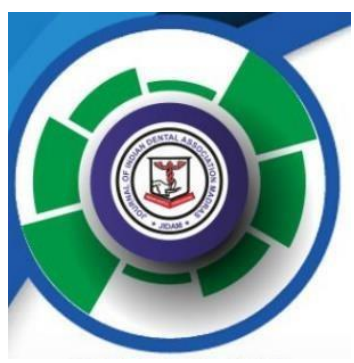

CASE REPORT

\title{
SURGICAL MANAGEMENT OF HEMANGIOPERICYTOMA/SOLITARY FIBROUS TUMOUR OF BUCCAL MUCOSA- A CASE REPORT
}

Dr. Mathew Jose, Dr. Sajesh, Dr. Nandagopan, Dr.Effie Edsor, Dr.Sindhuja Devi, Dr.Sowmya.

Department of Oral and Maxillofacial Surgery, Sree Mookambika Institute of Dental Sciences, Kulasekharam, Tamilnadu, India

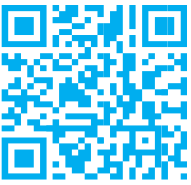

DOI: 10.37841/jidam_2021_V8_I2_07

Address for correspondence:

Dr. Effie Edsor, MDS,

Assistant Professor,

Department of Oral and Maxillofacial Surgery,

Sree Mookambika Institute of Dental Sciences, Kulasekharam,

Tamilnadu, India

Email: effieedsor@gmail.com

Received: 18.02.2021 First Published: 07.06.2021

Accepted: 31.03.2021

Published: 27.06.2021

\section{ABSTRACT}

Hemangiopericytomas (HPCs)/Solitary fibrous tumors are rare neoplasms of vascular origin that occur in head-and-neck region. These tumors arise from capillary pericytes and are difficult to distinguish from other tumors of vascular origin. HPC, initially described by Stout and Murray in 1942, usually occur in the fifth decade of life and account for 3\%-5\% of all soft-tissue sarcomas and $1 \%$ of all vascular tumors. The tumors usually occur in limbs, pelvis, or head-and-neck region; $15 \%-30 \%$ of all HPCs occur in head and neck. This is a report of a case of HPC located in the right buccal area of a 51-year-old woman.

KEYWORDS: Capillary pericytes, hemangiopericytoma, Immunohistochemistry, vascular tumor 


\section{INTRODUCTION: -}

Solitary fibrous tumour is an unusual vascular neoplasm of oral cavity which is not clinically distinguishable from other lesions. First described by Stout \& Murray in $1942^{1}$, they are tumours of pericytes of Zimmermann, which are baroreceptors on luminal wall of vascular channels ${ }^{8}$. Pericytes are mesenchymal in origin and are relatively undifferentiated in the sense that they can apparently develop into several different cell types including smooth muscle. They are contractile and can change their shape, thereby reducing the diameter of the capillary lumen ${ }^{4}$. It usually occurs in fourth to fifth decade of life. STFs may show many growth patterns and therefore can be easily mistaken for other more common H\&N spindle cell or epithelial lesions ${ }^{10}$. Haemangiopericytoma (HPC) has over the years been used fairly loosely, to describe a wide variety of neoplasms which have certain morphological characteristics in common: a monotonous appearance at low-power examination, moderate to high cellularity, and the presence of numerous, variably thickwalled, branching 'staghorn' vessels ${ }^{5}$. We report a case of HPC of the right buccal mucosa in a 51-year-old female patient.

\section{CASE REPORT:-}

A 51-year-old female presented with gradually enlarging asymptomatic mass in her right buccal mucosa for the past 4 months (Fig 1: (a)). The asymptomatic lesion was initially small which gradually enlarged to the present size of $5 \mathrm{~cm} \times 4 \mathrm{~cm}$, which was solitary \& well-circumscribed (Fig 1: (b)). The overlying mucosa appeared smooth \& mildly erythematous with no visible ulcerations or pulsations. Blanching was seen on the postero inferior aspect of swelling due to impingement of 48. The mass was rubbery in consistency. No lymphadenopathy. The examination of other sub sites of oral cavity was normal.

She had no compounding medical history or any recent history of trauma to the offending site. CT guided incisional biopsy reported it to be hemangio endothelioma. Immunohistochemistry for the same revealed strongly positive CD34.

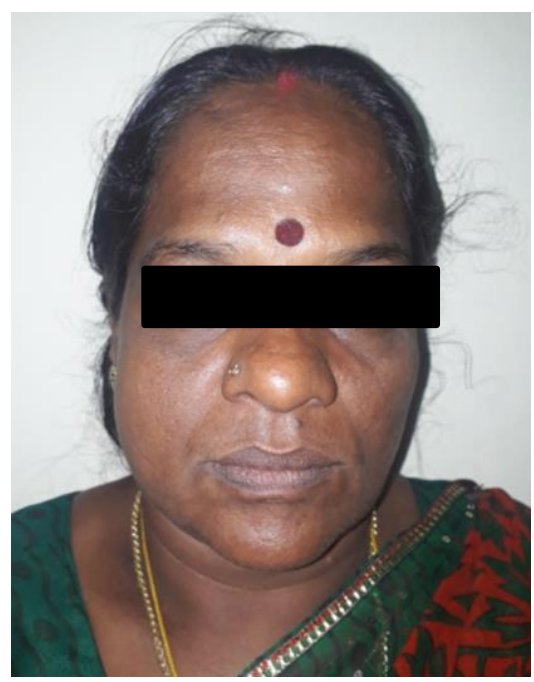

Fig 1:( a)

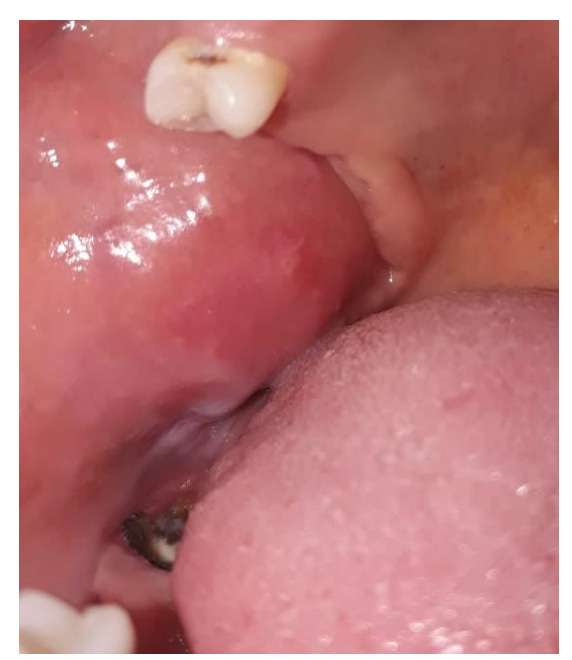

Fig 1: (b)

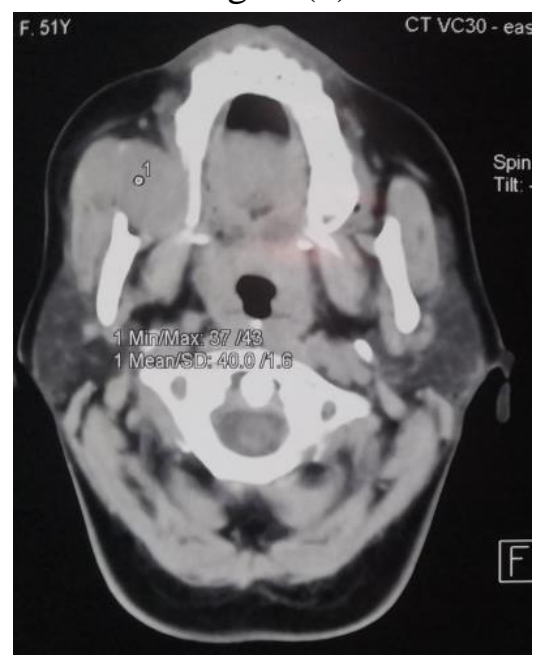

Fig 1:(c)

Volume No: 8, Issue No: 2 


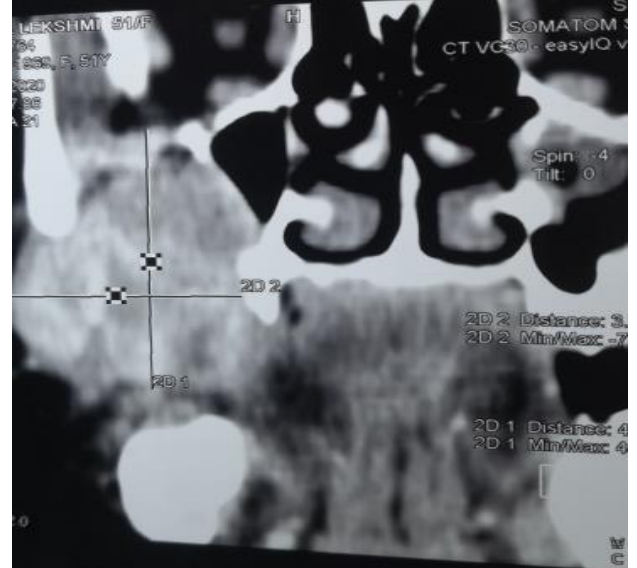

Fig 1: (d)

Fig 1: (a) Extra-oral photograph: an asymptomatic mass in her right cheek (b) Intra-oral photograph: a painless submucosal mass in the right buccal region (c) CT axial cut showing ill-defined heterogenous lesion in right buccal space with infiltration into adjacent masseter, temporalis muscle \& pressure erosion of maxilla (d) CT coronal cut showing radiopaque mass in the right buccal space measuring 4.43 X $3.56 \mathrm{~cm}$

\section{TREATMENT AND PROGNOSIS: -}

Surgery was conducted under general anaesthesia. A $7.0 \mathrm{~cm}$ transcutaneous incision at the right buccal mucosa was made parallel to the anterior border of the mandible ramus. The identified anatomic layers included the mucosa and the buccinator muscle. The tumor was found adjacent to the front part of the buccinator muscle. The tumor was encapsulated with connective tissue. It was easily separated from the layer structure. The tumor was ablated with extracapsular dissection. The patient was discharged 4 days after the surgery. There have been no signs of facial nerve injury or recurrence at 12 months post-operatively. Macroscopically, the cut section of the resected specimen showed a circumscribed erythematous mass measuring $6 \times 4$ $\times 2 \mathrm{~cm}$ surrounded by a fibrous capsule

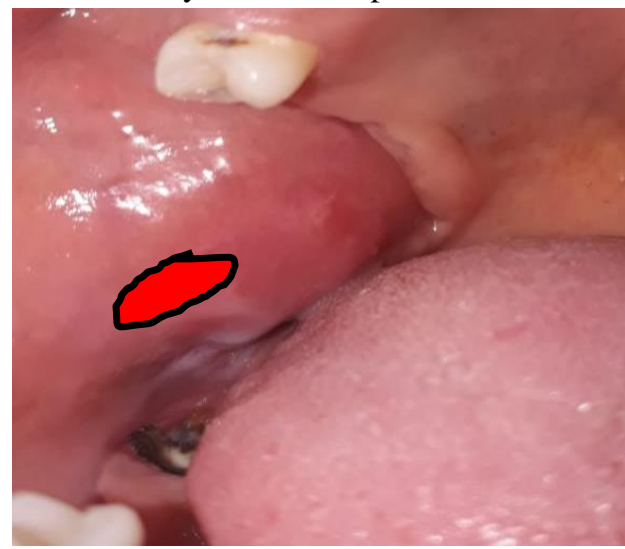

Fig 2:( a)

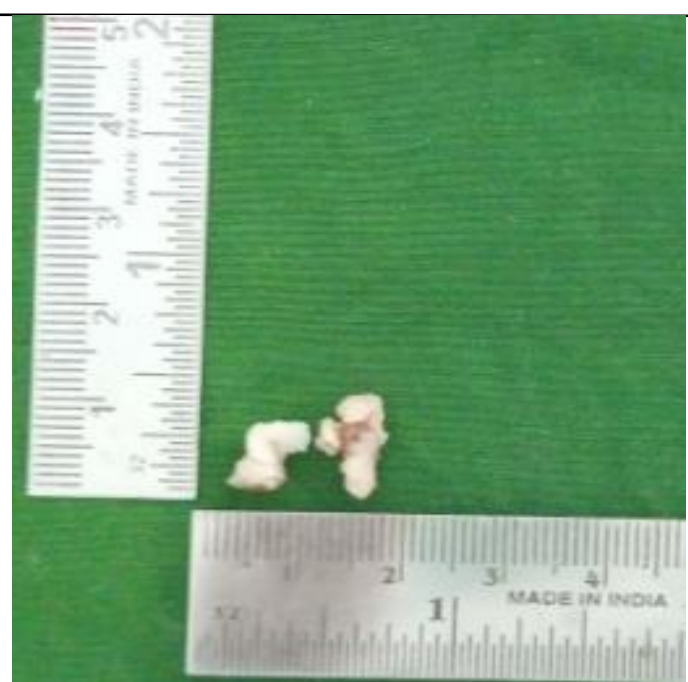

Fig 2: (b)

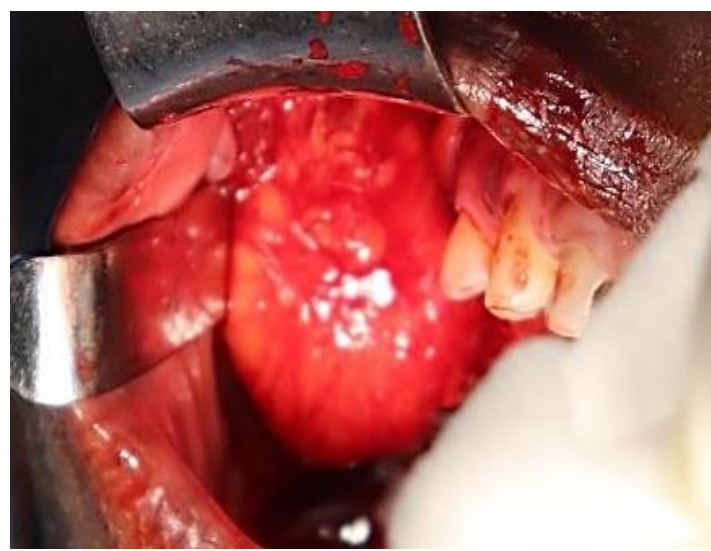

Fig 2:( c)

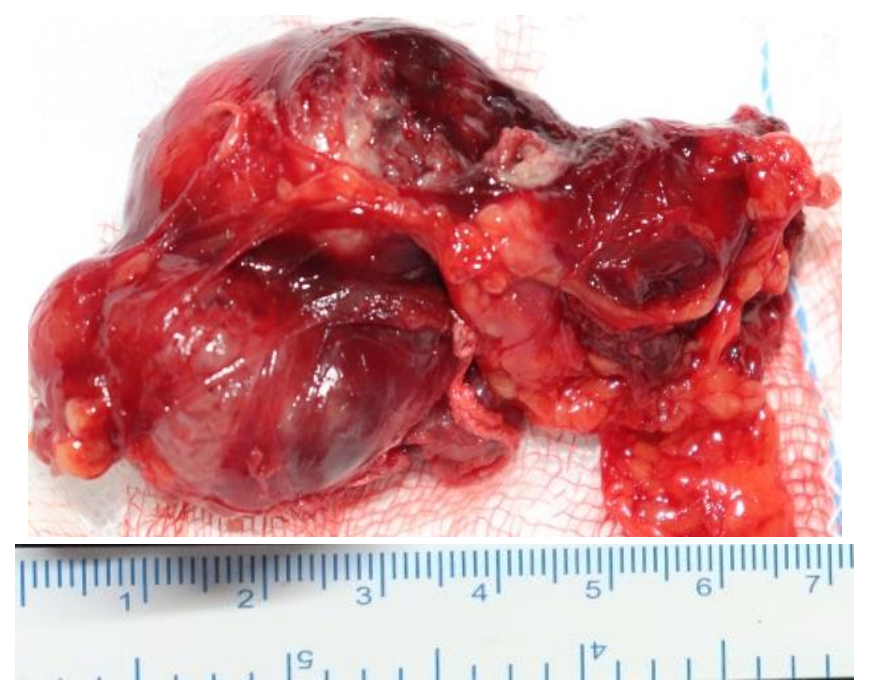

Fig 2: (d)

Fig 2: (a) Incisional biopsy site (b) specimen sent for histopathological examination(c) tumor seen encapsulated with connective tissue (d) Gross appearance of the resected specimen. A well-circumscribed nodular mass measuring 6 $\times 4 \times 2 \mathrm{~cm}$ surrounded by a fibrous capsule

Volume No: 8, Issue No: 2 
Mathew et al: Hemangiopericytomas /Solitary fibrous tumors of Oral Mucosa

\section{HISTOPATHOLOGIC FINDINGS: -}

Excised tissue sent for histopathological examination. Histopathology report revealed the presence of neoplasm composed of spindle cells with thin ectactic vascular channels in between. The cells have moderate amount of clear vacuolated cytoplasm \& plump mild to moderate pleomorphic nuclei. Mitosis 2-3/hpf in areas. Stroma shows areas of sclerosis. The tumor was labelled as benign HPC because of its of cellular atypia and presence of mitotic activity. The morphological and immunohistochemical features were consistent with the diagnosis of solitary fibrous tumor/hemangiopericytoma.

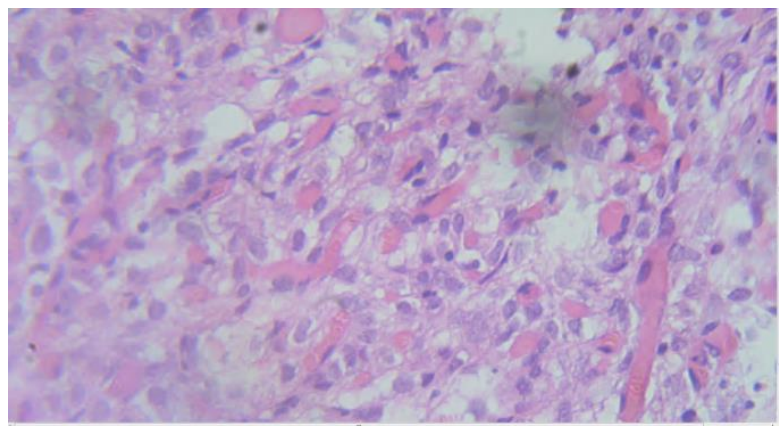

Fig 3:( a)

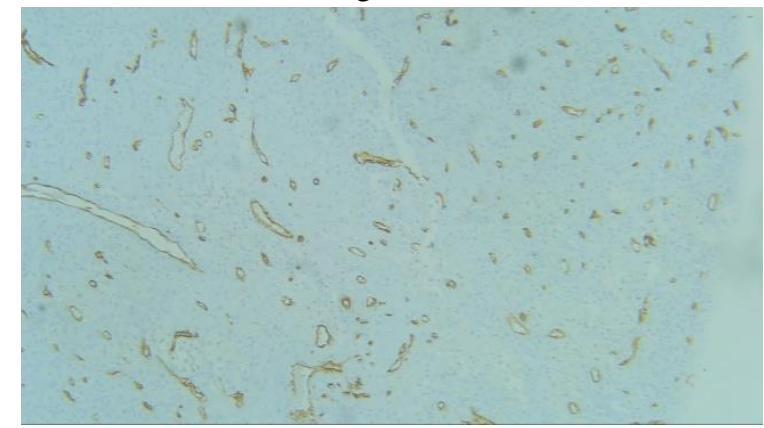

Fig 3: (b)

Fig 3:( a) The tumor comprised spindle cells with an irregular disposition associated with collagen bands and vascular structures branched with an evident lumen (b) Tumor cells showed strong positivity for CD34 (IHC).

\section{DISCUSSION: -}

Hemangiopericytomas are benign neoplasms with malignant potential. The sinonasal tract and orbit were the most common sites involved (30\% and $25 \%$ ), followed by the oral cavity and salivary glands $(15 \% \text { and } 14 \%)^{7}$. They are distinguished based on occurrence of metastasis and recurrence. The appearance on a plain radiograph is not specific. Usually, it presents as radiopaque soft tissue mass. Calcification may occur, but is uncommon. A CT scan and magnetic resonance imaging may aid in identification of the lesion. Angiograms may show evidence of rapid circulation indicated by a richly vascular mass with dilation of the arteries and a diffuse capillary blush or opacification in the arterial phase and dilation of the draining veins in the vicinity of the tumor in the venous phase $^{2}$. Recent IHC evidences now suggest that conceptually this tumor is not derived from the pericyte because it does not express actin or myofibroblastic markers. There is considerable histologic overlap between myofibroma, solitary fibrous tumor, synovial sarcoma, and mesenchymal chondrosarcoma. That is why, the diagnosis of HPC is the diagnosis of exclusion. Chan et $\mathrm{al}^{19}$ have summarized the essential diagnostic criteria for the diagnosis of SFT which was augmented by strong immunohistochemical CD34 positivity which is a consistent finding in most SFT's confirming the diagnosis. Malignant SFT's are very rare and account to $10-15 \%$ of all cases in pleura while in oral cavity there are only two reported cases. Furthermore, there are no unifying histologic criteria that appear to reliably and consistently predict malignancy in SFT. The management of HPC involves wide surgical excision. In the head and neck, cervical lymphadenectomy is reserved for those instances where palpable lymphadenopathy is coexistent. The role of radiotherapy has been questioned because these tumors are generally radioresistant. One study showed that only $13 \%$ of patients were cured with radiotherapy. The recurrence rate of SFT occurring in the pleura is reported to be approx. $30 \%$. In contrast, recurrence of an SFT in an oral lesion is rare ${ }^{13}$. More importantly, clinicians should keep in mind that a patient with a past history of SFT can show a malignant relapse even when the pathological features indicated a benign SFT in the first diagnosis. Thus, a continuous long term follow-up is needed for SFT patients.

\section{CONCLUSION}

Despite the rarity of HPC, it can be considered as one of the differential diagnosis of tumors of the head and neck region. Though surgical excision is the most accepted management of HPC. Early diagnosis reduces the postsurgical morbidity. Since, local recurrences are very common and late distant metastasis has reported, long-term follow-up, is mandatory both clinically and radiologically.

\section{FINANCIAL SUPPORT AND SPONSORSHIP}

Nil

\section{CONFLICT OF INTEREST:}

There are no conflicts of interest.

\section{REFERENCES: -}

1. Enzinger FM, Smith BH. Hemangiopericytoma. An analysis of 106 cases. Hum Pathol 1976; 7:6182. [PubMed] [Google Scholar]

Volume No: 8, Issue No: 2 
Mathew et al: Hemangiopericytomas /Solitary fibrous tumors of Oral Mucosa

2. Goldwasser, M. S., \& Daw, J. L. (1990). Hemangiopericytoma of the palate: Casereport. Journal of Oral and MaxillofacialSurgery 48(2), 211-215. doi:10.1016/s0278-2391(10)80214.

3. Requena L, Kutzner H. Hemangioendothelioma. Semin Diagn Pathol. 2013 Feb;30(1):29-44. doi: 10.1053/j.semdp.2012.01.003. PMID: 23327728.

4. Raghani N, Raghani MJ, Rao S, Rao S. Hemangiopericytoma/Solitary fibrous tumor of the buccal mucosa. Ann Maxillofac Surg 2018;8:151-3.

5. Gengler C, Guillou L. Solitary fibrous tumour and haemangiopericytoma: evolution of a concept. Histopathology. 2006 Jan;48(1):63-74. doi: 10.1111/j.1365-2559.2005.02290.x. PMID: 16359538

6. Unni, K. K., Ivins, J. C., Beabout, J. W., \&Dahlin, D. C. (1971). Hemangioma, hemangiopericytoma, and hemangioendothelioma (angiosarcoma) of bone. Cancer, 27(6), 1403-1414. doi:10.1002/1097-

0142(197106)27:6<1403::aidcncr2820270621>3.0 .co;2-6

7. Smith SC, Gooding WE, Elkins M, Patel RM, Harms PW, McDaniel AS, Palanisamy N, UramTuculescu C, Balzer BB, Lucas DR, Seethala RR, McHugh JB. Solitary Fibrous Tumors of the Head and Neck: A Multi-Institutional Clinicopathologic Study. Am J SurgPathol. 2017 Dec;41(12):16421656. doi: 10.1097/PAS.0000000000000940. PMID: 28877055; PMCID: PMC5680135.

8. Vanza B, RaiA,Khare N, et al. BMJ Case Rep 2020;13:e239135. doi:10.1136/bcr-2020-239135.

9. Weber, W., Henkes, H., Metz, K. A., BergDammer, E., \& Kühne, D. (2001).Haemangiopericytoma of the nasal cavity. Neuroradiology, 43(2), 183-186. doi:10.1007/pl00006046

10. Baněčková $\mathrm{M}$, Martínek $\mathrm{P}$, Skálová A, Mezencev R, Hadravský L, Michal M, Švajdler M. Solitary fibrous tumors of the head and neck region revisited: a single-institution study of 20 cases and review of the literature. Hum Pathol 2020 May;99:1-12. doi: 10.1016/j.humpath.2020.03.007. Epub 2020 Mar 23. PMID: 32217090.

11. Bauer JL, Miklos AZ, Thompson LD. Parotid gland solitary fibrous tumor: a case report and clinicopathologic review of 22 cases from the literature. Head Neck Pathol. 2012 Mar;6(1):21-31. doi: 10.1007/s12105-011-0305-8. Epub 2011 Oct 16. PMID: 22002440; PMCID: PMC3311954.

12. Chen H, Xiao CW, Wang T, Wu JS, Jiang CC, Qian J, Wei $\mathrm{CH}$, Wang XQ. Orbital solitary fibrous tumor: a clinicopathologic study of ten cases with long-term follow-up. ActaNeurochir (Wien). 2012 Feb;154(2):249-55; discussion 255. doi: 10.1007/s00701-011-1254-4. Epub 2011 Dec 28. PMID: 22203231

13. Okui T, Ibaragi S, Kawai H, Sasaki A. Solitary Fibrous Tumor Arising in the Buccal Space. Case Rep Med 2019 Oct 9;2019:9459837. doi: 10.1155/2019/9459837. PMID: 31687030; PMCID: PMC6803731.

14. Nunes FB, Sant'Ana MSP, Silva AMB, Agostini M, Silva Canedo NH, de Andrade BAB, Romañach MJ, Corrêa DL, Tomasi RA, Radhakrishnan R, Gomez RS, de Sousa SF, Brennan PA, Fonseca FP. Solitary fibrous tumour of the oral cavity: An update. J Oral Pathol Med 2020 Jan;49(1):14-20. doi: 10.1111/jop.12953. Epub 2019 Sep 15. PMID: 31424136.

15. Smith MH, Islam NM, Bhattacharyya I, Cohen DM, Fitzpatrick SG. STAT6 Reliably Distinguishes Solitary Fibrous Tumors from Myofibromas. Head Neck Pathol 2018 Mar;12(1):110-117. doi: 10.1007/s12105-017-0836-8. Epub 2017 Jul 8. PMID: 28689369; PMCID: PMC5873490.

16. Bajpai, Manas\&Pardhe, Nilesh\&Chandolia, Betina\&Arora, Manika. (2017). Solitary Fibrous Tumor / Hemangiopericytoma of Palate - Report of a Case with Immunohistochemical Interpretation Using CD 34. Journal of the College of Physicians and Surgeons Pakistan. 27. 457-458.

17. Vimi S, Punnya VA, Kaveri H, Rekha K. An aggressive solitary fibrous tumor with evidence of malignancy: a rare case report. Head Neck Pathol. 2008 Sep;2(3):236-41. doi: 10.1007/s12105-0080073-2. Epub 2008 Jul 31. PMID: 20614322; PMCID: PMC2807562.

18. Soriano-Hernández MI, Husein-ElAhmed H, RuízMolina I. Solitary fibrous hemangiopericytoma of atypical location: importance of immunohistochemical study. Cir Cir. 2014 MayJun;82(3):323-7. PMID: 25238475

19. Chan JKC. Solitary fibrous tumor-everywhere, and a diagnosis in vogue. Histopathology. 1997;31:568-76. doi:10.1046/j.13652559.1997.2400897.

20. Veltrini VC, Etges A, Magalhães MH, de Araújo NS, de Araújo VC. Solitary fibrous tumor of the oral mucosa--morphological and immunohistochemical profile in the differential diagnosis with hemangiopericytoma. Oral Oncol 2003 Jun;39(4):420-6. doi: 10.1016/s13688375(02)00148-3. PMID: 12676265 